\title{
Interesse dos servidores da Universidade Federal de Uberlândia por temas de Psicologia*
}

\author{
Sandra Augusta de Melo Neves ${ }^{1}$ \\ Pontifícia Universidade Católica de Campinas
}

\author{
Joaquim Gonçalves Coelho Filho ${ }^{2}$ \\ Universidade Federal de Uberlândia
}

\begin{abstract}
O estudo relatado neste artigo integra os propósitos do PREPSI - Laboratório de Estudos e Pesquisas em Psicologia Preventiva da Pontifícia Universidade Católica de Campinas. Neste sentido, busca mapear a receptividade de servidores (professores e técnico-administrativos) da Universidade Federal de Uberlândia com relação a textos de enfoque psicológico a serem publicados em jornal informativo de distribuição gratuita veiculados mensalmente junto a seus contracheques. Responderam espontaneamente aos questionários $4,0 \%$ do total de servidores, que demonstraram boa receptividade à iniciativa ( $93,8 \%$ dos participantes). Os assuntos de maior interesse foram: família, estresse, educação e desenvolvimento humano.

Palavras-chave: prevenção; clínica preventiva; psicologia social; difusão de psicologia; comunicação em psicologia.
\end{abstract}

\begin{abstract}
Interest of Uberlândia Federal University's officials of psychological themes

The studie reported in this paper is part of the purposes of PREPSI - Studies and Researchs in Prevent Psychology Laboratory of the Pontifícia Católica University of Campinas. It searchs to identify the level of receptivity of Uberlândia Federal University's servants (teaching and administrating staff) about psychologycal texts if they were published in a free monthly journal, attached with their paycheck. $4,0 \%$ of the servants answered spontaneouslly the research and show a high receptivity by the purpose ( $93,8 \%$ participants). The temes they show highly interested were: family, stress, education and humam development.

Key words: prevention; preventive clinic; social psychology; diffusion of psychology; communication in psychology.
\end{abstract}

A presente pesquisa insere-se em uma série de trabalhos desenvolvidos por um grupo de profissionais empenhados na fundação do Laboratório de Estudos e Pesquisas em Psicologia Preventiva da Pontifícia Universidade Católica de Campinas - PREPSI — que deverá ser implementado como um órgão oficial da referida Instituição.

\footnotetext{
* A iniciativa da pesquisa contou com o apoio da coordenadora do Grupo de Psicologia Clínica Preventiva Prof $\mathrm{Dr}^{\mathrm{a}}$ Regina Maria Leme Lopes Carvalho e dos membros do grupo. Já a construção do instumento de coleta de dados contou com a supervisão da $\operatorname{Prof}^{\mathrm{a}} \mathrm{Dr}^{\mathrm{a}}$ Eliana Martins da Silva Rosado.

1. Doutoranda em Psicologia na PUC-Campinas; bolsista/ CNPq. Endereço para correspondência: Rua Tahiti, 109. Jardim Nosso Recanto, CEP 38400-246, Uberlândia, MG.

2. Doutorando da PUCCAMP e bolsista CAPES.
}

A principal meta deste laboratório será desenvolver trabalhos de pesquisa e estudos sobre a prevenção primária em Psicologia, respaldados por uma visão dinâmica da mente e do homem.

Desde o final do ano de 1995, os doutorandos em Psicologia pela PUC-Campinas vêm publicando artigos sobre diversos temas em um jornal gratuito distribuído em vários bairros da cidade de São Paulo. Os textos são elaborados em linguagem simples, dando acesso ao público leigo, e trazem sempre a discussão de um tema comum à vida das pessoas sob um enfoque dinâmico, isto é, oferecendo uma compreensão do assunto. A discussão fundamenta-se na teoria psicanalítica ou psicodinâmica e trata os as- 
suntos de forma a oferecer ao leitor uma compreensão de pontos que comumente são desconhecidos da população, assim como parâmetros para que possam discernir quando a ajuda de um profissional se faz necessária.

Não obstante esta iniciativa tivesse sido muito bem recebida pelo veículo de comunicação e por seu público leitor, mostrou-se carente de informações mais sistematizadas quanto ao interesse do público. Por outro lado, a população atingida pelo veículo oferecia dificuldades em ser acessada para uma investigação neste sentido.

Esta dificuldade e o interesse em estender o trabalho de divulgação a outras populações levaram a que a pesquisa pudesse, neste primeiro momento, ser realizada num espaço e com uma população circunscritos. A população - os servidores de uma Universidade — , e o jornal anexado ao contracheque - ofereciam uma ótima oportunidade para a investigação da pertinência deste tipo de intervenção preventivista, já que a divulgação dos temas dar-se-á em um veículo que asseguradamente todos os funcionários recebem mensalmente.

Com os resultados da presente investigação, espera-se obter indicadores daquilo que ocorre em um nível mais geral, ou seja, naquelas populações cujo acesso é bem mais difícil para este tipo de pesquisa, como o público de um outro jornal gratuito distribuído, por exemplo, nas ruas de uma grande cidade.

Importante ressaltar que a escolha dos sujeitos decorreu ainda da necessidade da própria Instituição em que se deu a pesquisa em investigar a viabilidade de medidas preventivas para sua comunidade interna.

A Universidade Federal de Uberlândia conta com um serviço de atendimento ao servidor no qual uma equipe de saúde mental recebe um alto índice de demanda por atendimentos. Em decorrência disto, a necessidade de atua- ções em prevenção primária é de interesse evidente para o serviço, que não consegue atender à totalidade dos casos de atendimento.

\section{Importância da prevenção}

Prevenção é uma palavra da qual muito se ouve falar hoje em dia nos meios acadêmicos. Isto pode ser observado nas publicações e nos títulos de projetos, dissertações e teses, que vão "a campo" buscar respostas às questões suscitadas pela prática. Entretanto, o próprio conceito de prevenção exige uma postura de proximidade com a população em geral, com o meio extra-acadêmico/extra-muros. Nas universidades, as atuações neste tipo de abordagem estão contempladas naquilo que se chama de extensão.

Sair das paredes protetoras da academia conservando seus preceitos, respeitando sua preocupação com métodos, com terminologias, com o rigor científico, não constitui absolutamente algo fácil de se pôr em prática. Existe o risco de que propostas que possam efetivamente trazer uma resposta à população - fim último de toda ciência e da existência das universidades - sejam abortadas antes de sua implementação quando são confrontadas com possibilidades de fracasso que exporiam a própria academia. Entretanto, este é um risco necessário.

Bion (1970) ilustra-nos bem a necessidade da ciência ser tornada como bem comum:

"Graças a Faraday e a cientistas outros, gente como a gente ilumina uma sala com um toque de interruptor; graças a Freud e colaboradores, pessoas comuns esperam que a psicanálise elucide a mente. $O$ fato de que a atividade universal se execute por gente comum torna imperativa a descoberta científica (ou a 
divulgação ou simplificação ou comunicação de todas reunidas)." (pp.89-90)

É preciso, portanto, enfrentar os riscos de atuações num nível mais "popular", ou não será possível efetivar qualquer devolução significativa do conhecimento produzido àquilo que se constitui na razão de ser da produção acadêmica: a comunidade, a população mais geral.

Vários são os autores e as correntes que defendem uma postura mais ativa por parte do Psicólogo, dos quais vale ressaltar Caplan (1964) e Garcia (1992), além dos movimentos com ênfase preventivista cuja expressão máxima é a Psiquiatria Comunitária.

A discussão sobre a prevenção em saúde mental, entretanto, não é conclusiva do ponto de vista teórico, mas investe massivamente em uma alteração no eixo da atuação do profissional e visa atentar o agente de saúde para o engajamento e o compromisso com as políticas sanitárias voltadas para as populações mais amplas.

A informação como medida preventivista é algo bastante novo e carente de investigações, sendo um campo em que o PREPSI pretende investir com pesquisas, dentre as quais esta é apenas uma das iniciativas. Este interesse decorre da crença de que a informação é na realidade o primeiro nível da prevenção.

Tal qual nos legam Kaplan e Sadock (1985), o objetivo da prevenção primária é atuar no período pré-patogênico, através da eliminação de agentes etiológicos e da redução de fatores de risco. Isto poderia ser feito, por exemplo, através de ações integradas de psicohigienistas em programas gerais de saúde pública, como a participação em palestras e em seminários de orientação sobre doença mental ou programas de orientação antecipatória para pessoas que vão viver situações estressantes. $\mathrm{O}$ acesso à informação é, portanto, um dos canais considerados num nível mais elementar de prevenção.

É nesta perspectiva que a presente pesquisa vem fazer um mapeamento que ofereça informações sobre os interesses de uma clientela específica - servidores de uma Universidade Federal - - para a qual se pretendia implantar um programa de Psicologia preventiva através do oferecimento de textos de reflexão e de orientação sobre diversos temas ligados ao dia-a-dia das pessoas.

Para isto, foram elaboradas questões que pudessem oferecer dados sobre a população, sobre os temas de interesse dos servidores, e suas opiniões acerca da iniciativa de utilizar como veículo o jornal anexado ao contracheque, ou seja, de circulação gratuita.

\section{Objetivo geral}

Investigar o posicionamento de sujeitos quanto ao seu interesse e seu envolvimento com temas de Psicologia veiculados via jornal gratuito, bem como caracterizar a população interessada.

\section{Objetivos específicos}

Identificar a gama de temas de interesse dos sujeitos em assuntos ligados à Psicologia.

Avaliar o uso do jornal gratuito como veículo de mediação desses temas a esses leitores.

\section{Procedimentos}

O instrumento de coleta de dados apresentava duas partes: uma, voltada para a caracterização do sujeito (campus de origem, cargo ou função, sexo, faixa etária e grau de instrução), e outra, contando com dez questões, sendo oito de múltipla escolha, uma aberta e uma mista, que visavam levantar o posicionamento dos sujeitos quanto ao assunto investigado. 
Com estas questões procurou-se explorar variáveis relativas ao interesse dos leitores quanto a temas de Psicologia, ao veículo gratuito e ao jornal anexado ao contracheque mais especificamente, buscando a qualificação de indicadores quanto aos seguintes aspectos: temas de maior interesse; hábito de leitura destes temas; condições de credibilidade para estes temas; hábito de leitura de jornais gratuitos; interesse por artigos sobre Psicologia anexados ao contracheque; probabilidade de leitura do artigo; probabilidade de que tais artigos desenvolvessem atitude positiva diante de um atendimento psicológico; opinião geral sobre a idéia de oferecer tais temas gratuitamente.

A questão aberta $\left(n^{\circ} 10\right)$ visava levantar os motivos para a aprovação ou não da iniciativa, e a semi-aberta $\left(n^{\circ} 2\right)$ permitiu que fossem feitas sugestões de temas não contemplados nas alternativas oferecidas.

Foram enviados questionários a todos os 5642 servidores da Universidade Federal de Uberlândia, obtendo-se um retorno de 226 questionários $(4,0 \%)$. Este instrumento solicitava a colaboração das pessoas para se conhecer sua opinião e seu interesse em receber textos para a orientação e a reflexão sobre temas de Psicologia. Orientava os participantes a enviarem ou entregarem o mesmo preenchido em um setor responsável pelo atendimento de saúde dos servidores, que conta com sede nos diversos campi da Universidade. Vale destacar que um número não identificável de servidores não recebeu o contracheque dentro do período em que os questionários foram recolhidos (45 dias após sua emissão) devido a situações excepcionais como: cessão a outros órgãos federais, licenças e afastamentos.

Os questionários que retornaram ao setor de recebimento foram então recolhidos e tiveram seus resultados tabulados.

\section{Resultados}

A identificação dos sujeitos apresenta índices interessantes que podem, no mínimo, caracterizar a amostra dos participantes espontâneos na pesquisa e até oferecer indicadores sobre os leitores potenciais dos artigos, uma vez que também estes irão anexados aos contracheques (mesmo veículo usado para os questionários). Em termos de função ou cargo, os docentes tiveram uma maior participação, Fig. B $(36,7 \%)$, seguidos pelos técnicos em funções administrativas (assistentes, auxiliares e secretários: $26,5 \%$ ) e os técnicos de nível superior (20,0\%). Quanto ao sexo, 58,4\% (Fig. C) eram mulheres e a grande maioria das pessoas com idade entre 30 e 49 anos (82,3\%, Fig. D). A maior participação foi de pessoas com nível de escolaridade mais alto: 70\% (Fig. E) com curso superior completo ou pós-graduação.

$\mathrm{O}$ interesse por temas ligados à Psicologia está presente em 93,8\% (Fig.1) das respostas, sendo que dos 10 temas consultados, os que mais se destacam são relativos à família, estresse, educação e desenvolvimento humano (Fig.2). Como sugestão espontânea, o tema que mais se destaca é sobre psicologia organizacional e recursos humanos. A freqüência com que esse leitor declara ler artigos sobre o tema também é bastante alta (Fig.3, 75,2\%), porém, o maior ou o menor envolvimento depende do jornal (Fig.4, 27,6\%) ou de quem nele escreve (Fig.4, 47,0\%). Quanto ao veículo, jornal gratuito, este é lido habitualmente por $66,8 \%$ dos respondentes (Fig.6). No caso específico de jornal anexado ao contracheque, veiculando temas de Psicologia, este despertaria o interesse em $72,1 \%$ das respostas (Fig.7), mas a sua leitura dependeria do tema desenvolvido. Diante da leitura de um artigo de Psicologia, 27,0\% das pessoas acreditam que seriam levadas a desejar um contato com um psicólogo após essa leitura, 

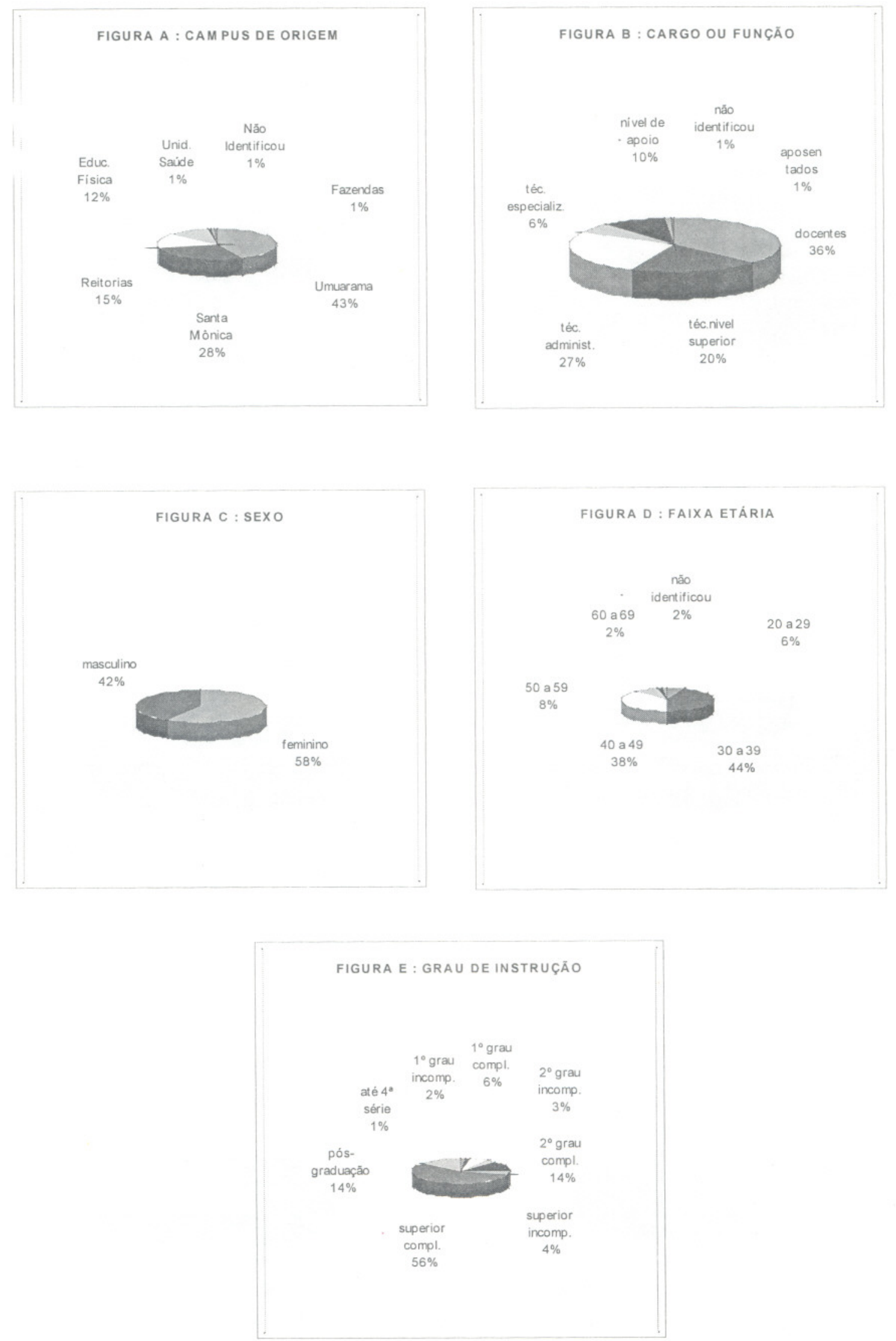

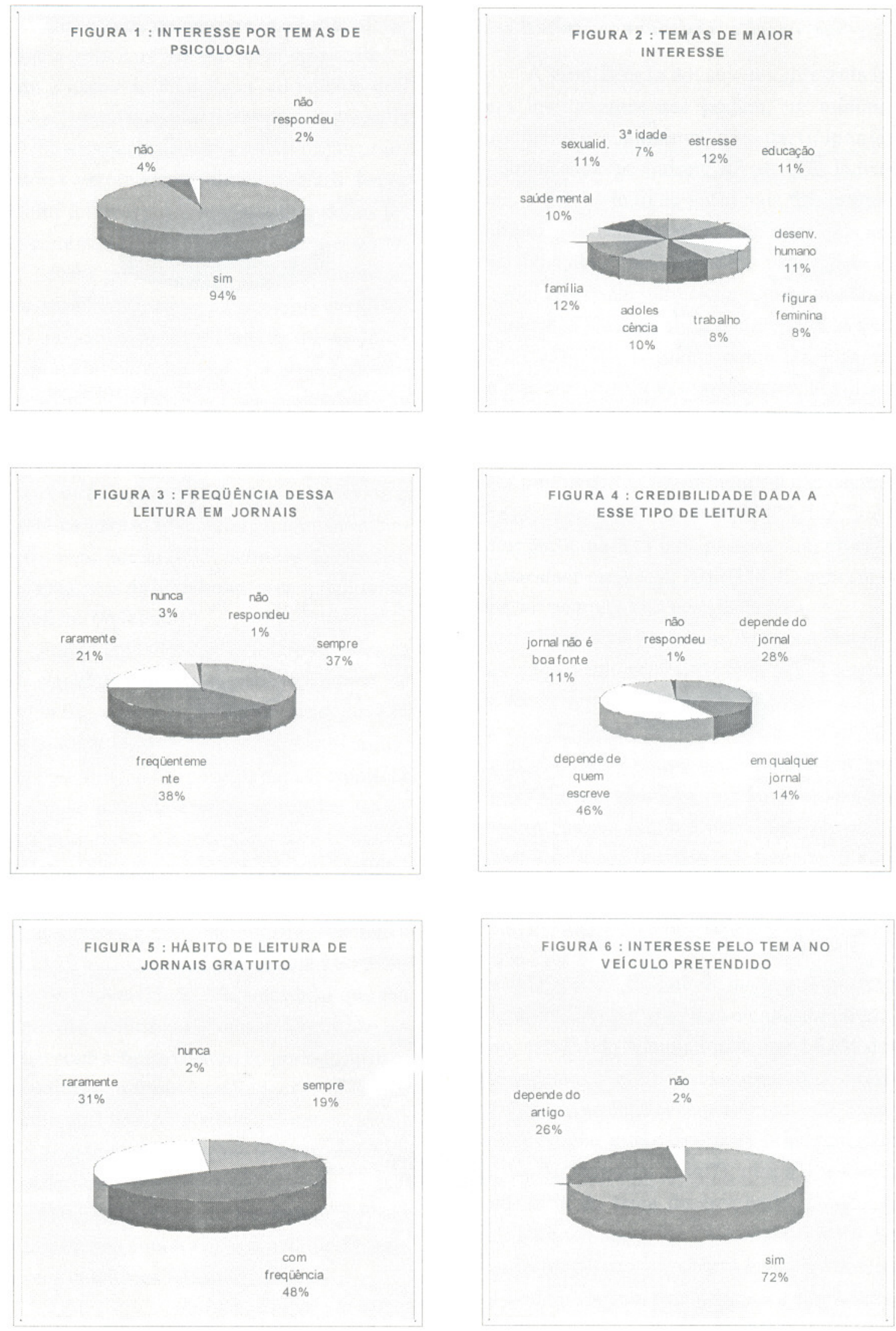

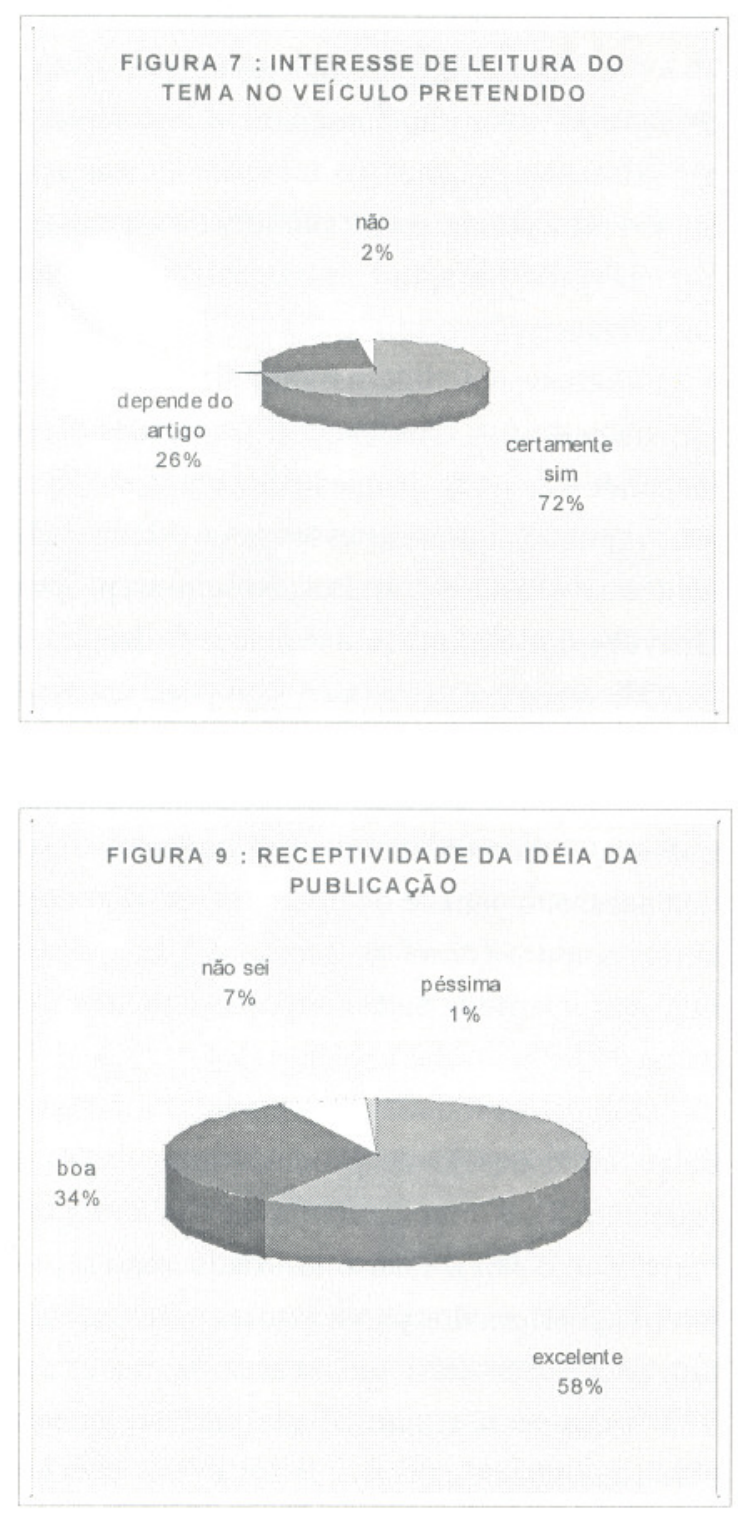

mas a maioria $(65,0 \%)$ acredita apenas em uma pequena probabilidade disto vir a acontecer (Fig. 8).

No geral, a idéia da publicação de artigos de Psicologia em jornal gratuito é vista como excelente e/ou boa em $92,5 \%$ das respostas (Fig.9). Solicitados a justificar a receptividade da iniciativa de divulgar temas de Psicologia junto aos contracheques, os
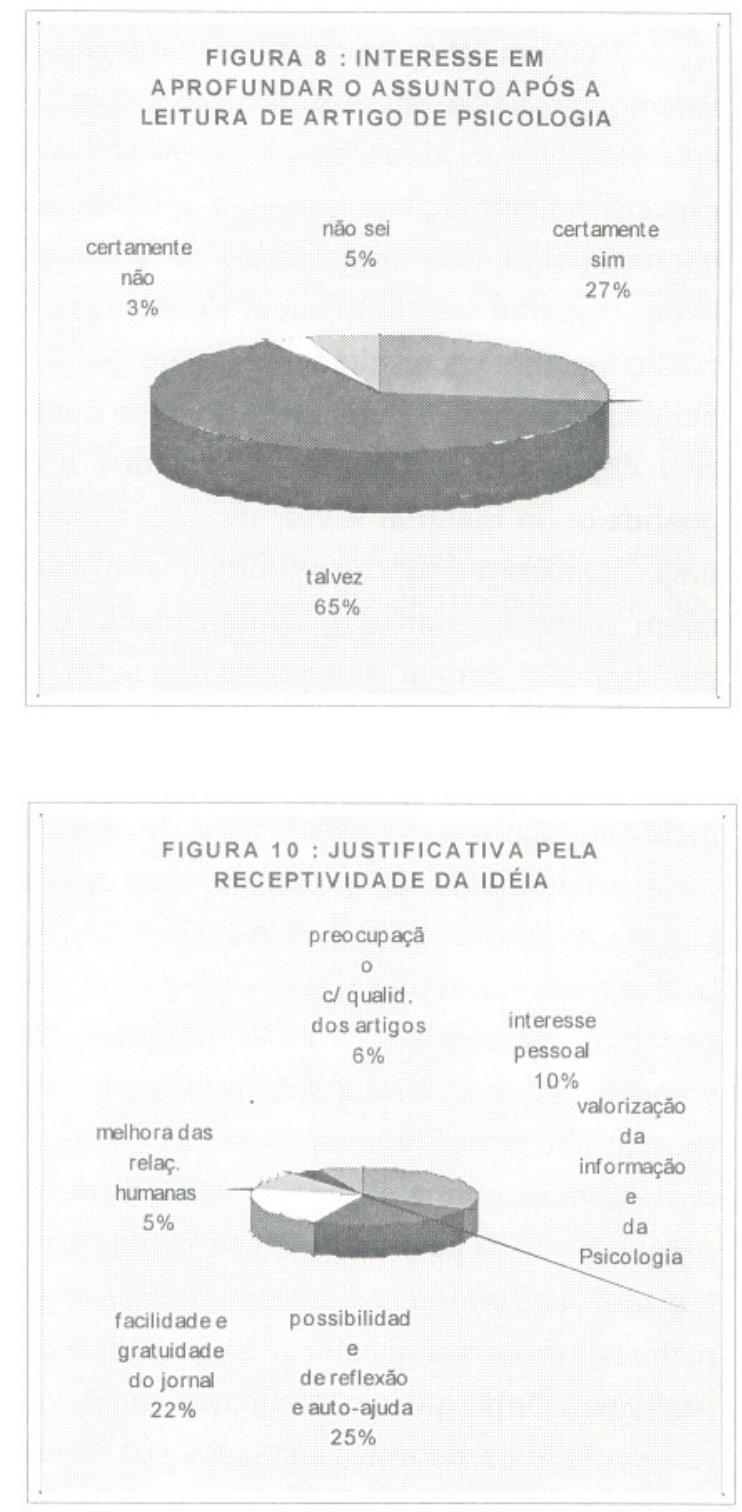

sujeitos deram como respostas mais freqüentes: valorização da informação e da Psicologia (33,0\%), a possibilidade de reflexão e auto-ajuda $(25,0 \%)$, a facilidade e a gratuidade do jornal $(22,0 \%)$, dentre outras (Fig. 10). Estas respostas foram submetidas a um processo de categorização, uma vez que a questão era aberta. 


\section{Discussão e Conclusões}

Evidenciou-se na pesquisa que temas de Psicologia são de interesse das pessoas e que elas consideram, ainda, que o jornal gratuito, especificamente aquele que vem anexado aos contracheques dos funcionários da Universidade, constitui um bom meio de divulgação para o assunto. Os resultados apontam que a fidelidade da leitura e a cristalização desta iniciativa dependerá dos temas veiculados e da qualidade do material divulgado. Há também uma consideração sobre a importância em saber quem escreve os artigos, demonstrando uma preocupação com a autoridade do autor no assunto abordado.

A identificação dos sujeitos mostra claramente um maior interesse por parte de camadas mais privilegiadas do ponto de vista profissional e de escolaridade. Este dado remete a outros questionamentos que, entretanto, não puderam ser elucidados nesta pesquisa, tais como: 1) a maior participação indica que estas pessoas têm mais interesse do que as outras, ou deve-se mais a uma atitude positiva diante de pesquisas? 2) as pessoas de níveis menos privilegiados culturalmente sentem-se à vontade para responder tais questões? 3) a amostra que participou da pesquisa corresponde àquela que realmente lê os informes anexados aos contracheques? Estas são questões que ficaram em aberto e apontam para a necessidade de novas investigações.

A faixa etária de 30 a 49 anos compreende a maioria maciça de participantes, mas é preciso considerar que não houve controle de amostra neste aspecto (nem em outros, já que a participação foi espontânea) e é provável que a maioria dos servidores da Universidade concentre-se nesta faixa. Esta observação é igualmente válida para o sexo, podendo a maioria feminina refletir a proporção existente na comunidade universitária ou mesmo na população geral.

A concentração nos diversos campi parece equivalente ao número de servidores distribuídos nos mesmos (o campus Umuarama, por exemplo, tem o maior número de servidores por abrigar o hospital universitário, além de unidades acadêmicas).

Um aspecto interessante diz respeito aos jornais gratuitos. Observações colocadas pelos respondentes junto às questões sobre este tema mostram que algumas pessoas consideram não ter acesso a jornais gratuitos, embora na própria Universidade circulem vários folhetins $\mathrm{e}$ periódicos com este caráter. Isto pode estar associado ao fato de que "jornais" é um termo que as pessoas remetem a um formato específico de publicação que não condiz com aqueles a que têm acesso: o papel e o tamanho são diferentes, assim como a forma de acesso e a linguagem que comumente é usada nos jornais comercializados.

A possibilidade de que a leitura pudesse despertar o desejo de procurar um psicólogo (questão 8) é maciçamente aceita com um "talvez" $(65,0 \%)$. Este é um dado representativo da abertura dos participantes para um contato com um profissional da área. Somados aos $27,0 \%$ das pessoas que acham que "certamente sim", que teriam a necessidade de falar com um psicólogo despertada pelos artigos, perfazem $92,0 \%$ os participantes com uma atitude positiva para com os atendimentos psicológicos e, de maneira geral, com as orientaç̃os que podem ser feitas por um psicólogo. Embora este dado possa ser encarado com otimismo, é preciso ponderar o fato de que responder ao questionário já demonstra e indica que esta atitude existe. Por outro lado, não se sabe o que isto significa para os outros $96,0 \%$ do total de servidores, já que os respondentes representam 4,0\% da população geral. 
A valorização da informação e da Psicologia aparecem, em primeiro lugar, como motivo para considerar positiva a iniciativa de publicar temas de Psicologia junto aos contracheques, ficando, em segundo lugar, a possibilidade de que tais temas tragam reflexão e autoajuda quanto às questões abordadas. Estas considerações feitas pelos participantes apontam de forma positiva para os propósitos da pesquisa: a prevenção pela divulgação da informação.

A presente pesquisa precedeu a divulgação dos textos ou artigos de caráter preventivo, versando sobre assuntos comuns, da vida cotidiana das pessoas e deverá, em um momento posterior, ter nova etapa para avaliar os resultados deste trabalho.

Tal iniciativa já se mostrou frutífera dentro da Instituição, tendo redundado na mobilização de profissionais de seu quadro funcional na elaboração e divulgação de textos sobre os assuntos mais solicitados na pesquisa. Este fato pode ser considerado um efeito positivo e secundário da pesquisa, uma vez que o envolvimento de profissionais locais no projeto foi uma iniciativa dos mesmos.

Com o panorama traçado por esta investigação, será possível direcionar os artigos para temas de maior interesse e necessidade do público e, por outro lado, comparar os dados obtidos com novas pesquisas de igual natureza que serão levadas adiante, por integrantes do PREPSI, para outras populações.

Após aproximadamente um ano de divulgação dos temas, pretende-se, como adiantado acima, realizar nova investigação que ofereça dados sobre o efetivo alcance da iniciativa diante dos leitores. Dessa maneira, será possível, mais do que sobre o interesse, retrabalhar os efeitos preventivos da informação com discussões dinâmicas sobre temas de Psicologia para este público.

\section{Referências}

Bion, W.R. (1970). Atenção e interpretação: o acesso científico à intuição em psicanálise e grupos. Trad.Paulo Dias Corrêa. Rio de Janeiro: Imago, 1991.

Caplan, G. (1964). Princípios de psiquiatria preventiva. Trad.Álvaro Cabral. Rio de Janeiro: Zahar, 1980.

Garcia, J.L.T. (1992). Atención primaria en salud mental y salud mental en atención primaria. Barcelona: Doyma.

Kaplan, H.S. \& Sadock, B.J. (1985). Comprehensive textbook of psychiatry IV. Baltimore/London: Williams \& Wilkins. 